\title{
Usefulness and Limitations of Left Ventricular End-Systolic Indices, End-Systolie Volume and Left Ventricular Peak Systolic Pressure/End-Systolic Volume Ratio
}

\author{
YOHICHIRO FURUTA, MASUAKI FUJIYAMA, JUN MATSUMURA, \\ FUMIHIKO UTSU* AND HIRONORI TOSHIMA \\ Department of Internal Medicine, Kurume University School of Medicine and \\ *Institute of Cardiovascular Diseases, Kurume University School of Medicine, \\ Kurume, 830 Japan
}

Received for publication November 26, 1981

\begin{abstract}
Summary: Left ventricular (LV) end-systolic indices have been rarely investigated fundamentally or clinically in assessing $\mathrm{LV}$ function. Diagnostic catheterization and LV angiography were performed in 83 subjects (normal and various heart diseases) and LV end-systolic volume (ESVI) and LV peak systolic pressure/ESVI ratio (LVSP/ESVI) were calculated. These LV endsystolic indices were compared with LV ejection fraction (EF) in assessing LV function and functional capacity. These two indices, especially LVSP/ ESVI, were more useful than EF in detecting diseased hearts, except the pressure-overloaded or hypertrophic hearts, and in evaluating the functional capacity of individual patients. However, some limitations and problems are apparent, first, these indices are influenced by afterload, second, they do not take into account LV wall-thickness or LV mass, and third, we cannot yet directly assess them for LV contractility indices. We conclude that ESVI and LVSP/ESVI are useful indices in assessing LV function, particularly in detecting diseased hearts and in assessing clinical functional capacity and prognosis. These indices could be simply and non-invasively applied using echocardiogram and the blocd pressure cuff.
\end{abstract}

Key words: left ventricular (LV) function - LV end-systolic indices - LV end-systolic volume $-\mathrm{LV}$ peak systolic pressure/end-systolic volume ratioejection fraction - functional capacity

\section{Introduction}

It is well known that the function of ejecting left ventricle is determined by the interaction of preload, afterload, myocardial contractility, heart rate, ventricular geometry, valvular function and coronary circulation. Left ventricular volume indices, for example, stroke volume or ejection fraction, are necessarily composed of two volume factors: end-diastolic and end-systolic volume. Left ventricular end-diastolic volume index (EDVI) is clinically substituted for the index of preload and has been utilized as one of the important indices in assessing left ventricular (LV) function (Patterson, 1914; Sarnoff, 1954). On the other hand, endsystolic volume index (ESVI) has not been thoroughly investigated for clinical use, though Mitchell and Wildenthal (1972) suggested it as an important factor of $\mathrm{LV}$ function and contractility. Recently, LV peak systolic pressure/end-systolic volume 
ratio (LVSP/ESVI), presented as systolic tone by Kats (1960), has been systematized as Emax by Suga and co-workers (1973, 1974, 1976, 1977), which has been applied to the clinical evaluation of $\mathrm{LV}$ contractility. Emax, standard function curve (Sarnoff, 1954), and the concept of afterload-mismatch (Ross, 1976) are the parameters for the two dimensinal analysis of $\mathrm{LV}$ responses to certain acute loadings. These may prove to be more important concepts and approaches in evaluating $\mathrm{LV}$ function and contractility. However, in most clinical circumstances, unloading and single-measured indices are desirable although they, too, have limitations. Previously we reported that LVSP/ ESVI ratio closely correlated with $\mathrm{LV}$ ejection fraction (EF) and indices of the shortening velocity (fractional shortening and peak $d p / d t / P$ ), and this ratio was one of the useful indices in evaluating the LV function (Fujiyama, 1980).

The purpose of present study is to examine the usefulness and the limitations of these LV end-systolic indices, ESVI and LVSP/ESVI, in comparison to EF that has been evaluated as ejection phase index of LV function, and in assessing the clinical functional capacity or severity of cardiac patients.

\section{Subjects and Methods}

Eighty three subjects were investigated. The group was composed of 11 controls with normal left ventricular function including neuro-circulatory asthenia and variant angina of intact coronary arteries, 8 cases of mitral stenosis (MS), 9 cases of mitral regurgitation (MR), 5 cases of aortic stenosis (AS) including 2 combined with mild aortic regurgitation (AR), 12 cases of AR, 9 cases of hypertensive heart disease (HHD) including 2 asymmetrical septal hypertrophy (ASH), 5 cases of non-obstructive hypertrophic cardiomyopathy (HCM), 8 cases of congestive cardiomyopathy (CCM), 10 cases of anterior and/or septal old myocardial infarction (MI ant) and 6 cases of inferior old myocardial infarction (MI inf). The mean age of the subjects was 49.6 years old. Diagnostic cardiac cathetelization and LV angiography (right anterior oblique) were performed. LV volumes were measured by the area-length method and corrected by the equation of Kennedy and coworkers (1970). The end-diastolic and end-systolic volume were determined by the maximal and minimal volume of $L V$, respectively. They were corrected by the body surface area (BSA). Left ventricular peak systolic pressure (LVSP) was measured using the fluid-filled catheter (NIH or Sones catheter 7 or $8 \mathrm{~F}$ ) immediately before left ventriculography, and the ratio of LVSP to ESVI (LVSP/ESVI) was calculated. Each correlation coefficient and best fit equation were calculated from Hewlet-Packard computer. Statistical analysis in individual groups were made using a Student's $t$ test.

\section{Results}

Values of left ventricular systolic pressure, volume, EF and LVSP/ESVI are summarized in Table 1. Fig. 1 presents the mean and standard deviation of EF, ESVI and LVSP/ESVI in control subjects and each disease group. EF in diseased hearts was comparatively lower than that in control subjects except AS. The value in HCM was higher than in control. However, EF of diseased hearts overlapped values for controls, except CCM.

ESVI was significantly larger in MR, $\mathrm{AS}, \mathrm{AR}, \mathrm{CCM}$ and $\mathrm{MI}$ than in control. Larger ESVI was also demonstrated in AS combined with AR and in decompensated HHD. However, ESVI in HCM was smaller. In cases of HCM and pressure-overloaded hearts (AS and HHD), LVSP/ 
TABLE 1

Value of left ventricular systolic pressure (LVSP), end-diastolic or systolic volume (EDVI or ESVI), Ejection Fraction (EF) and LVSP/ESVI in control and diseased hearts. Each value shows the mean and standard deviation.

\begin{tabular}{|c|c|c|c|c|c|c|c|c|c|c|}
\hline no & Control & $\underset{(8)}{\operatorname{MS}}$ & $\underset{(9)}{\mathrm{MR}}$ & $\underset{(5)}{A S}$ & $\underset{(12)}{\operatorname{ARR}}$ & $\underset{(9)}{\mathrm{HHD}}$ & $\underset{(5)}{\mathrm{HCM}}$ & $\underset{(8)}{\mathrm{CCM}}$ & $\underset{(10)}{\text { MIant }}$ & $\underset{(6)}{\operatorname{Minf}}$ \\
\hline $\operatorname{LVSP}(\mathrm{mmHg})$ & $\begin{array}{l}133 \\
\pm 20.7\end{array}$ & $\begin{array}{c}126 \\
\pm 11.3\end{array}$ & $\begin{array}{l}127 \\
\pm 18.3\end{array}$ & $\begin{array}{l}206 \\
\pm 66.1\end{array}$ & $\begin{array}{l}145 \\
\pm 24.2\end{array}$ & $\begin{array}{c}164 \\
\pm 26.3\end{array}$ & $\begin{array}{l}119 \\
\pm 13.4\end{array}$ & $\begin{array}{l}108 \\
\pm 6.9\end{array}$ & $\begin{array}{c}121 \\
\pm 14.7\end{array}$ & $\begin{array}{l}133 \\
\pm 32.5\end{array}$ \\
\hline $\begin{array}{l}\mathrm{EDVI} \\
\left(\mathrm{ml} / \mathrm{m}^{2} \mathrm{BSA}\right)\end{array}$ & $\begin{array}{l}61 \\
\pm 1.38\end{array}$ & $\begin{array}{l}50 \\
\pm 12.7\end{array}$ & $\begin{array}{l}107 \\
\pm 24.3\end{array}$ & $\begin{array}{l}105 \\
\pm 41.6\end{array}$ & $\begin{array}{c}138 \\
\pm 36.2\end{array}$ & $\begin{array}{l}68 \\
\pm 20.1\end{array}$ & $\begin{aligned} & 55 \\
\pm & 9.6\end{aligned}$ & $\begin{array}{c}129 \\
\pm 29.2\end{array}$ & $\begin{aligned} & 96 \\
\pm & 18.1\end{aligned}$ & $\begin{array}{l}80 \\
\pm 11.8\end{array}$ \\
\hline $\begin{array}{l}\text { ESVI } \\
\left(\mathrm{ml} / \mathrm{m}^{2} \mathrm{BSA}\right)\end{array}$ & $\begin{aligned} & 20 \\
+ & 7.0\end{aligned}$ & $\begin{aligned} & 22 \\
\pm & 8.0\end{aligned}$ & $\begin{array}{l}50 \\
\pm 17.9\end{array}$ & $\begin{array}{l}38 \\
\pm 23.2\end{array}$ & $\begin{array}{l}64 \\
+22.3\end{array}$ & $\begin{array}{l}29 \\
\pm 13.7\end{array}$ & $\begin{aligned} & 14 \\
\pm & 4.2\end{aligned}$ & $\begin{array}{l}98 \\
+22.8\end{array}$ & $\begin{aligned} & 50 \\
\pm & 20.0\end{aligned}$ & $\begin{array}{l}36 \\
\pm \\
\pm .2\end{array}$ \\
\hline $\mathrm{EF}$ & $\begin{array}{r}0.68 \\
\pm 0.07\end{array}$ & $\begin{array}{r}0.58 \\
\pm 0.11\end{array}$ & $\begin{array}{r}0.54 \\
\pm 0.10\end{array}$ & $\begin{array}{r}0.64 \\
\pm 0.18\end{array}$ & $\begin{array}{r}0.54 \\
\pm 0.06\end{array}$ & $\begin{array}{r}0.57 \\
\pm 0.12\end{array}$ & $\begin{array}{r}0.77 \\
\pm 0.09\end{array}$ & $\begin{array}{r}0.24 \\
\pm 0.05\end{array}$ & $\begin{array}{r}0.50 \\
\pm 0.11\end{array}$ & $\begin{array}{r}0.56 \\
\pm 0.07\end{array}$ \\
\hline $\begin{array}{l}\text { LVSP } / \mathrm{ESVI} \\
\left(\mathrm{mmHg} / \mathrm{ml} / \mathrm{m}^{2} \mathrm{BSA}\right)\end{array}$ & $\begin{array}{r}7.4 \\
\pm 2.9\end{array}$ & $\begin{array}{r}6.3 \\
\pm 1.7\end{array}$ & $\begin{array}{r}2.9 \\
\pm 1.1\end{array}$ & $\begin{array}{r}7.7 \\
\pm 6.3\end{array}$ & $\begin{array}{r}2.5 \\
\pm 0.8\end{array}$ & $\begin{array}{r}6.6 \\
\pm 2.9\end{array}$ & $\begin{array}{r}9.5 \\
\pm 3.5\end{array}$ & $\begin{array}{r}1.2 \\
\pm 0.3\end{array}$ & $\begin{array}{r}2.7 \\
\pm 0.9\end{array}$ & $\begin{array}{r}4.0 \\
\pm 1.4\end{array}$ \\
\hline
\end{tabular}

Abbreviations: $L V S P=$ left ventricular (peak) systolic pressure. $E D V I=$ end-diastolic volume index. $\quad E S V I=$ end-systolic volume index. $E F=$ ejection fraction. $B S A=$ body surface area. $\mathrm{MS}=$ mitral stenosis. $\mathrm{MR}=$ mitral regurgitation. $\mathrm{AS}=$ aortic stenosis. $\mathrm{AR}=$ aortic regur gitation. $\mathrm{HHD}=$ hypertensive heart disease. $\mathrm{HCM}=$ (non-obstractive) hypertrophic cardiomyopathy. $\mathrm{CCM}=$ congestive cardiomyopathy. $\mathrm{MI}$ ant=anterior and/or septal old myocardial infarction. MI inf=inferior old myocardial infarction.

\section{LVEF}
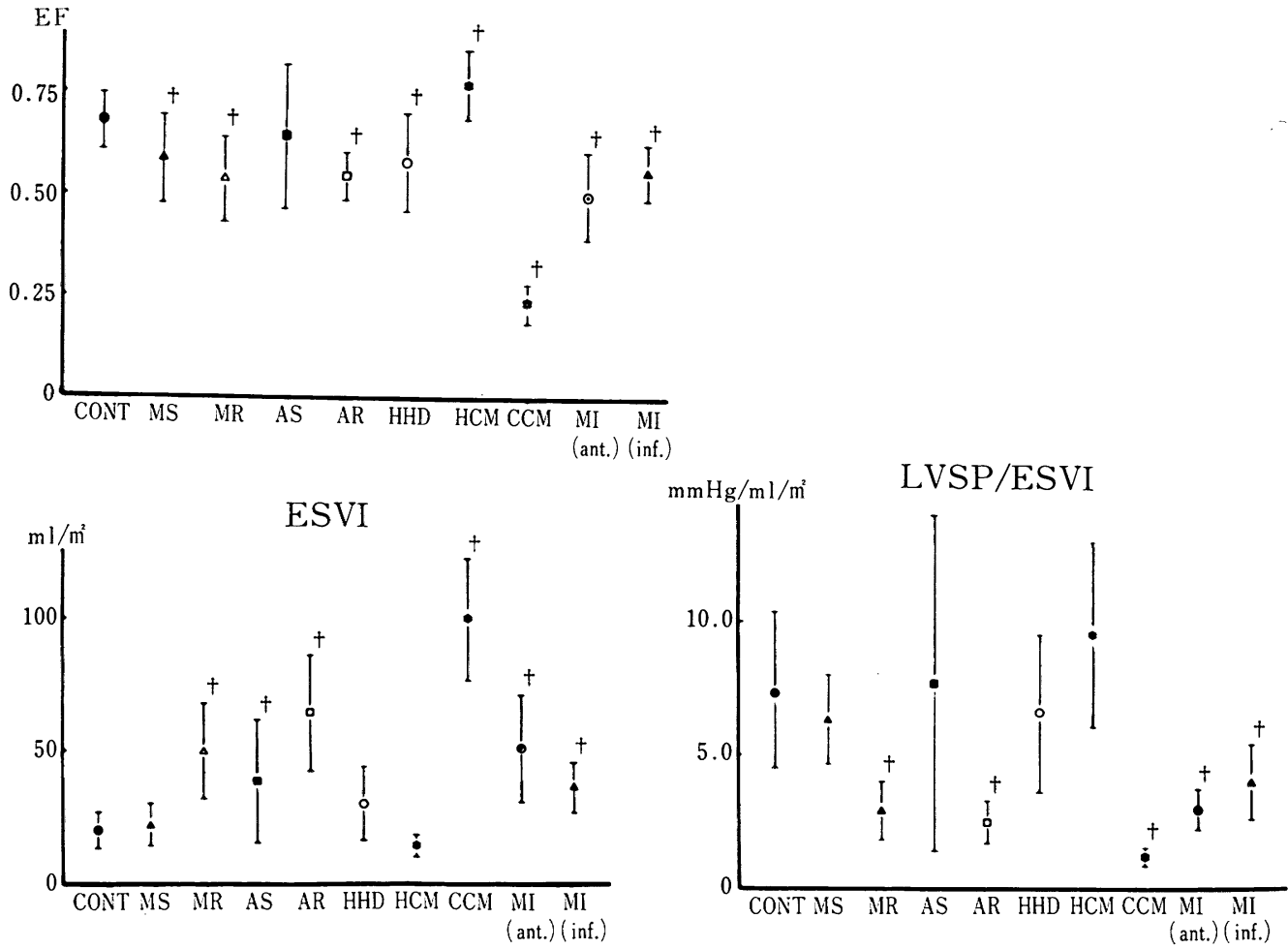

Fig. 1. Comparison of EF, ESVI and LVSP/ESVI in control and diseased hearts. Each value shows the mean and standard deviation. symbols $(\dagger)$ indicated statistical significance between control and each diseased heart $(p<0.05)$, and abbreviations are same as Table 1. 
ESVI was almost the same or slightly larger compared to control subjects, because of normal or decreased ESVI and/or increased LVSP. However, this ratio decreased in proportion to decompensation and failure in pressure-overloaded hearts. Furthermore, this ratio decreased in cases of volume-overloaded hearts (AR and MR) because of increased ESVI, and in cases of heart failure, for example, CCM and those cases of MI which were due to increased ESVI and depressed LVSP.

Fig. 2 shows the relationship of EDVI, ESVI, LVSP/ESVI and EF for all subjects. For EDVI and EF, $(\mathrm{EF})=1.40$ 0.19 ln (EDVI) with a correlation coefficient of 0.505 (Fig. 2 A). ESVI and EF were more closely related than EDVI and EF with correlation coefficient of 0.848 $[(\mathrm{EF})=0.96-0.04 \sqrt{(\mathrm{ESVI})}]$ in Fig. 2B, additionally, volume-overloaded hearts were situated at the upper portion in this curvilinear relation. EDVI and ESVI of these hearts were larger than that of other hearts in spite of a similar value of EF. ESVI in pressure-overloaded and hypertrophic hearts tended to be smaller than in control.

On the other hand, LVSP/ESVI was curvilinearly related to $\mathrm{EF}$ with correlation coefficient of $0.836 \quad[(\mathrm{EF})=0.31+$ $0.18 \ln (\mathrm{LVSP} / \mathrm{ESVI})]$ in Fig. $2 \mathrm{C}$.

Fig. 3 shows the relationship between LVSP/ESVI and EF using the regression equation of Fig. $2 \mathrm{C}$. When $\mathrm{EF}$ was 0.6 , 0.5 and 0.4, LVSP/ESVI approximately showed 5. 0, 3. 0 and 1.7, respectively. Similarly, when LVSP/ESVI was less than 1.0 and more than 4.0, EF showed less than 0.3 and more than 0.55 , respectively.

Fig. 4 shows the comparison of indi-
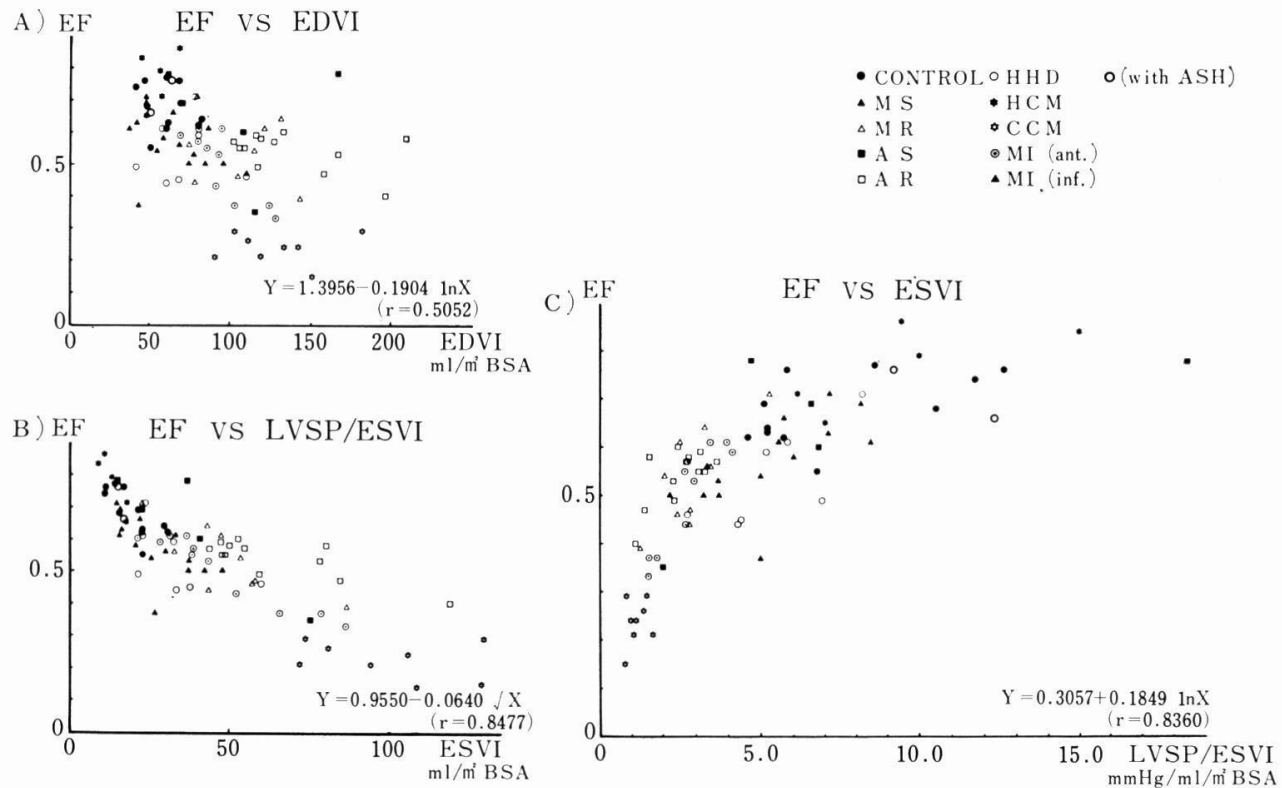

Fig. 2. Relation of EDVI, ESVI LVSP/ESVI and EF

A), B) and C) shows the relation of EDVI vs EF, ESVI es EF and LVSP/ESVI vs EF, respectively. Each relation is best fitted to the curvilinear and its correlation coefficients between ESVI, LVSP/ESVI and EF are higher than between EDVI and EF. 


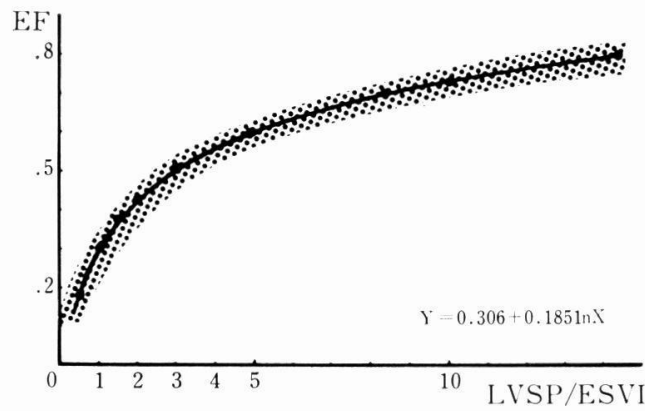

Fig. 3. Diagram of Relation between LVSP/ESVI and EF

This diagram is the theoretical curve represented by the equation in Fig. 2C).

vidual values of EF, ESVI and LVSP/ ESVI in control, HHD, MR, AR, CCM and $\mathrm{MI}$ (ant). In this figure, dashed horizontal lines represent lower and upper limit of control subjects for each parameter.

Individual values of $\mathrm{EF}$ overlapped between control subiects and patients with pressure, volume-overloaded hearts and
MI(ant). Patients with MR and AR under 0.4 of $\mathrm{EF}$ were severe cases. Its values were within normal limits in some patients with MI(ant). ESVI in volumeoverloaded hearts were larger than that in control, and ESVI more easily distinguished diseased hearts, except HHD, than did EF. In a few severe cases of MR and $\mathrm{AR}$, ESVI showed almost same values as that of CCM. Generally, values of CCM were larger than those of volume-overloaded hearts, especially of AR, in spite of similar EDVI in these groups. There was no statistically significant difference between control-HHD and MR-AR. Overlapping patients with MI(ant) and controls in ESVI were fewer than in EF. Results of LVSP/ESVI were similar to those of ESVI. But this ratio more clearly distinguished between control and these diseased hearts than did either EF or ESVI. A few severe cases of MR and AR showed almost the same values as CCM.

Fig. 5 shows the comparison of these indices and clinicel functional capacity or severity according to the classification of
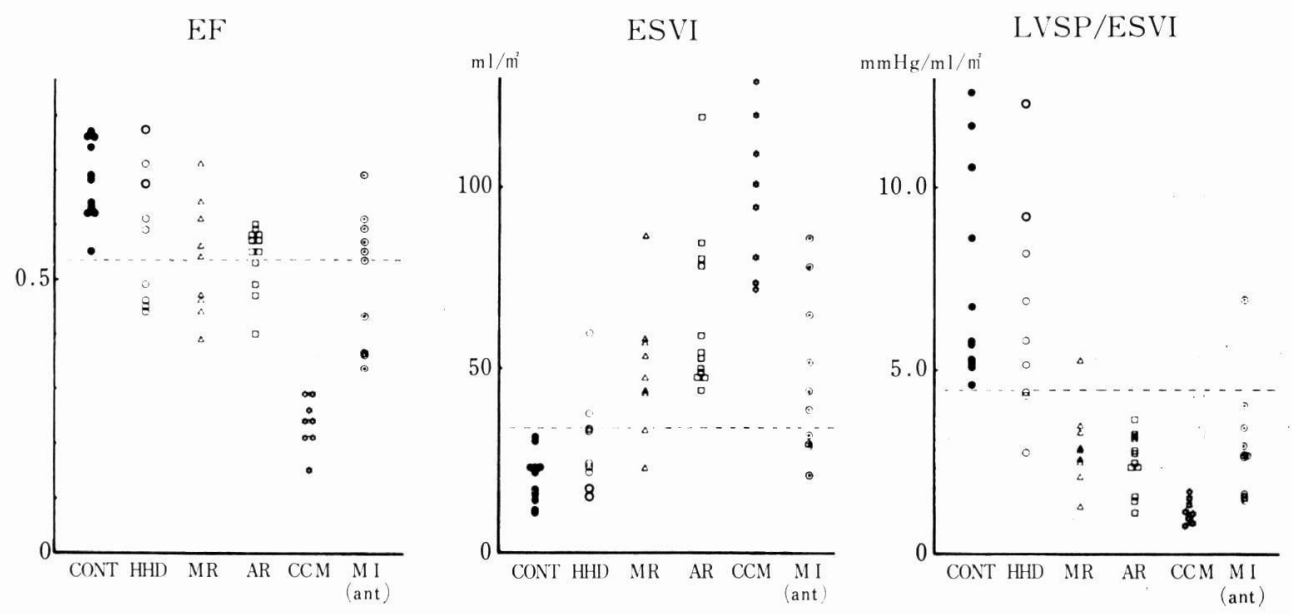

Fig. 4. Comparison of EF, ESVI and LVSP/ESVI in individual cases.

Dashed horizontal lines represent lower and upper limit of control subjects for each parameter. 

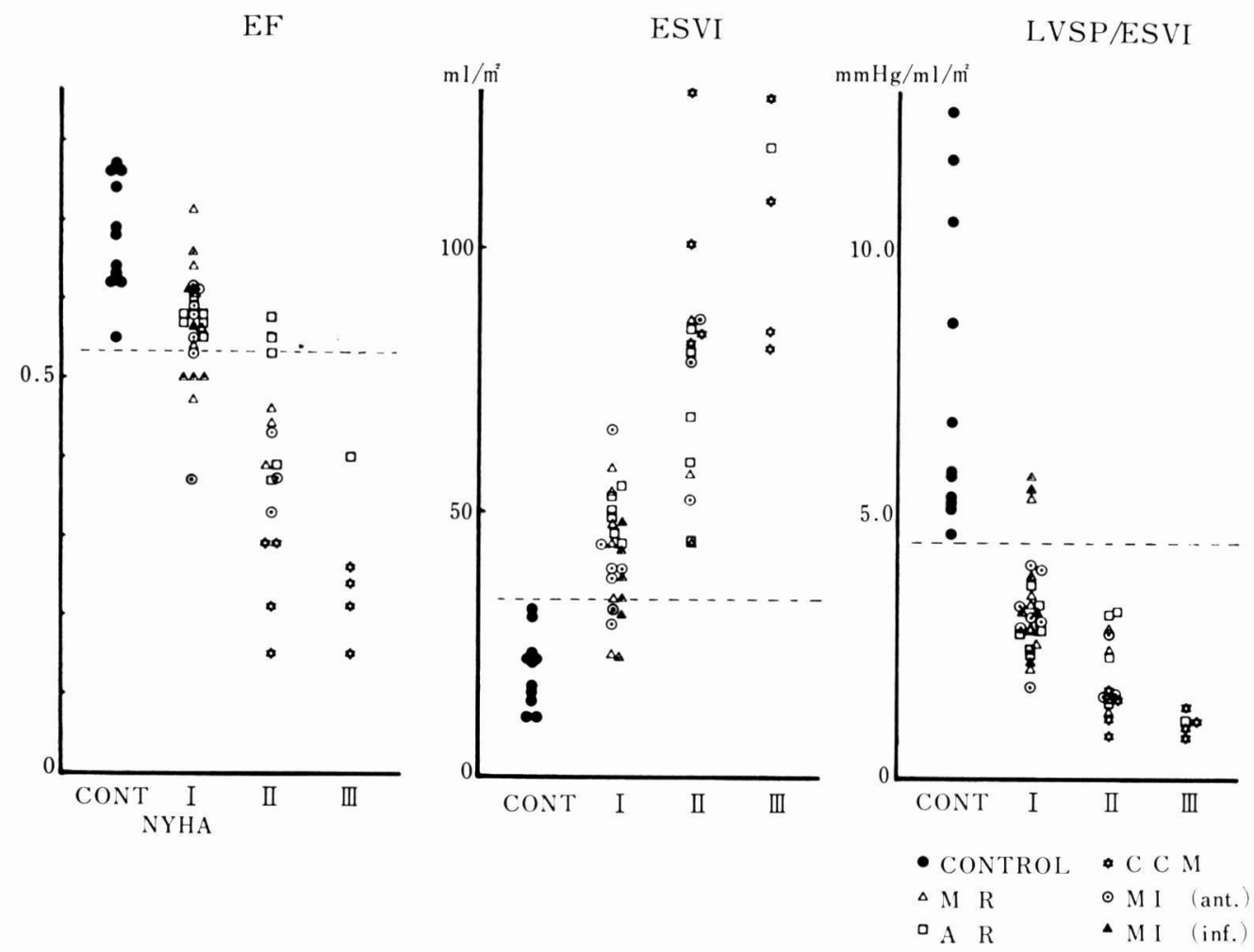

Fig. 5 Comparison of EF, ESVI, LVSP/ESVI and Functional capacity in Individual cases.

Functional capacity was classified by New York Heart Association (NYHA). Dashed horizontal lines represent lower and upper limit of control subjects for each parameter.

New York Heart Association (NYHA). All indices showed statistically significant differences between control subjects and patients of NYHA I, II, III, in addition, no overlap of populations was noted for controls and patients of NYHA III. There were more overlapped patients in EF between control, NYHA I and II.

On the other hand, ESVI and LVSP/ ESVI, particularly the latter more learly distinguished between control, NYHA I and II than did EF. Namely, overlapping patients between control and NYHA I, and between I and II were fewer in ESVI and LVSP/ESVI than in EF. ESVI and LVSP/ESVI entirely separated pa- tients of NYHA II and III to that of control. More patients of NYHA II and III overlapped according to these indices. Furthermore, the patients of NYHA II who showed increased ESVI, decreased LVSP/ESVI and who overlapped with patients of NYHA III in these indices, eventually demonstrated congestive heart failure after discharge and required surgical valvular-operations.

\section{Discussion}

Left ventricular function may be assessed by distingushing between pump 
function and myocardial or ventricular contractility. However, indices indicating only myocardial or ventricular contractility, that is, independent of loading, preload, afterload and heart rate, are not presently available. Evaluation of left ventricular response to certain acute loadings usually performed by pharmacological or mechanical changes of afterload and preload and which employ two dimensional analysis are important since the main purpose of assessing left ventricular function and contractility is to establish the available reserve. In these circumstances, the standard cardiac function curve (Sarnoff, 1954), concepts of afterload-mismatch (Ross, 1976) and Emax (Suga, 1973, $1974,1976,1977)$, that is, the slope value of end-systolic pressure-volume relation, which has recently seen clinical application to the left ventricle (Weisfeldt, 1976; Grossman, 1977; Sasayama, 1979; Marsh, 1979; Takahashi, 1980; Fujii, 1980), are useful methods. However, it is difficult and often impossible to perform the same loadings frequently and to all patients. Therefore, simple, single-measure, noninvasive indices are indispensable for clinical use.

The presented ESVI and LVSP/ESVI are indices of left ventricular end-systole. Although the meaning and relation of left ventricular end-systolic volume, dimension and end-systolic muscle length with respect to left ventricular function and contractility had not been entirely apparent, these are independent of preload, only slightly influenced by heart rate, and sensitive to afterload and contractility (Mitchell, 1972). Therefore, ESVI is an important volume factor in $\mathrm{LV}$ function and the present studies suggest that ESVI is more useful than EDVI as a singlemeasured index in assessing $\mathrm{LV}$ function and functional capacity. In particular, ESVI may estimate performance of LV function before complete compensation by the Frank-Starling mechanism, in volume- overloaded and failing hearts for which preload reserve is limited. Values of ESVI are within normal limits or lower than control values, in patients with HCM and pressure-overloaded hearts whose function are compensated only by thickening of $\mathrm{LV}$ wall (Sasayama, 1976), which gradually increases in the decompensated state proportionately to depressed myocardial contractility and appearance of the FrankStarling mechanism. Also, ESVI increases in cases of volume-overloaded hearts, CCM and a number of cases of MI. ESVI more readily distinguishes between control and diseased hearts than did EF in individual cases (Fig. 4 and 5), although Fig. 1 indicates that EF more readily distinguishes between control and diseased hearts than did either ESVI or LVSP/ESVI. ESVI is useful in detecting diseased hearts, except pressure-overloaded and other hypertrophic hearts, and also in evaluating functional capacity and in providing a prognosis (Borow, 1977).

On the other hand, LVSP/ESVI is the ratio which is near the upper left corner in left ventricular pressure-volume loop from resting state, and directly related to the maximal value of instantaneous pressure-volume ratio (Fujiyama, 1980; Nivatpumin, 1979; Higuma, 1980). This ratio is one basal point on the line of LV end-systolic pressure-volume relation, whose slope value is Emax, clinically produced by acute pressure-interventions. Though this ratio is not corrected for zero pressure, i. e. Vd or Vo and is theoretically different from Emax, this ratio may be significantly related to Emax, reported by Itaya (1981) and Matsuzaki (1980).

Recently, Nivatpumin and co-workers (1979) examined this ratio and concluded that it is more sensitive than EF in detecting subtle changes. But it was unknown whether this ratio more easily distinguished individual patients than other indices, since their results were obtained from diseased hearts as a group, for ex- 
ample, they did not distinguish between stenosis and regurgitation in mitral and aortic diseases.

The relationship between LVSP/ESVI and EF is significantly curvilinear and similar to the theoretical relationship between Emax and EF, established by Sagawa and co-workers (1977). In addition, we note that this ratio is curvilinearly related to the indices of myocardial shortening velocity (Fujiyama, 1980). These curvilinear relations are most important in discussing the superiority of this ratio to other indices. Inferring from Fig. $2 \mathrm{C}$ and 3, LVSP/ESVI may be useful in establishing subgroups for the critical levels of left ventricular pump function, for example, EF of over 0.5 , particularly between 0.5 and 0.6. That is to say, patients with LVSP/ESVI of over 4.5 have normal left ventricular function, and patients with values under 2.0 have severe dysfuntion and failing hearts. This ratio more readily distinguishes between control and diseased hearts, and it was comparable to or more sensitive than EF and ESVI in detecting diseased hearts except pressure-overloaded and other hypertrophic hearts. Furthermore, this ratio may be applied to the assessment of functional capacity, clinical severity and prognosis of cardiac patients. With non-invasive determination of systolic blood pressur/endsystolic dimension or volume ratio using echocardiogram and cuff-blood pressure, it is possible to follow the clinical course of cardiac patients (Itaya, 1981). The end-systolic indices under discussion, especially LVSP/ESVI, may complement the drawbacks of $\mathrm{EF}$ and other former parameters of left ventricular function.

However, there are some limitations to these indices. First, the values of these indices are directly influenced by afterload, especially ESVI. They must, therefore, be used with discretion, for example, in cases with hypotension and hypertension, or in subacute changes of systolic blood pressure following administration of antihypertensive or vasodilator drugs. Similarly, LVSP/ESVI in these cases are altered influencing the blood pressure irrelative to their $\mathrm{LV}$ function.

Second, these indices do not consider LV myocardial wall thickness. Wall thickening of left ventricle and normal or decreased ESVI in pressure-overloaded and other hypertrophic hearts indicate that LV function is normal or hyperkinetic until the heart fails (Sasayama, 1976, 1977; Takahashi, 1980). These patients were not distinguished from normal. However, it may be possible to incorporate the correction by LV mass or the ratio of myocardial wall stress to LV end-systolic volume and dimension (Marsh, 1979; Sasayama, 1979; Takahashi, 1980).

Third, relations between LVSP/ESVI, Emax and other indices of LV contractility are not fully clarified. Consequently, LVSP/ESVI cannot yet be evaluated as the index of LV contractility, although this ratio is generally independant of preload and heart rate but slightly influenced by afterload and sensitive to contractility. This ratio certainly correlates with Emax (Itaya, 1981; Matsuzaki, 1980), but its relationship is not exactly linear since it does not correct for zero pressure, i.e. $\mathrm{Vd}$, the ESV at zero end-systolic pressure obtained from $\mathrm{X}$-intercepts on LVESPESV lines. Vd increases in proportion to LV dysfunction (Grossman, 1977). Therefore, there is danger in a simple comparison to Emax, as this ratio is overestimated, particularly in patients with increased ESVI, for example, in volumeoverloaded and failing hearts.

In addition, it is unknown whether or not these indices are actually superior to other indices in assessing functional capacity and clinical course or prognosis of cardiac patients. Further fundamental and clinical investigations are required.

In conclusion, ESVI and LVSP/ESVI are useful indices in evaluating left ven- 
tricular function, particularly in detecting diseased hearts and in predicting clinical functional capacity and prognosis. These indices can be simply and non-invasively determined using echocardiogram and cuff-blood pressure.

\section{References}

Borow, K., Green, L.H., ManN, T., Sloss, L.H., Collins, J. J. Jr., Cohn, L. and Grossman, W. (1977). End-systolic volume as a predictor of postoperative left ventricular function in volume overload from valvular regurgitation. Circulation, Suppl III, III-40.

Fuji, J., Kuboki, M., Watanabe, M. and Kato, K. (1980). Comparative study of Emax, ejection fraction, Vcf and left ventricular function curve by echocardiography. J. Cardiography, 10, 451-458 (in Japanese).

Fujiyama, M., Furuta Y., Ikeda, H., Uemura, S., Itaya, M., Takahashi, H., Toshima, $H$. and UTsu, F. (1980). Experimental and clinical study of peak left ventricular systolic pressure/end-systolic volume (LVSP/ESVI) ratio as a index of left ventrciular function. J. Cardiography, 10, 831-841 (in Japanese).

Grossman, W., Braunwald, E., Mann, T., McLaurin, L.P. and Green, J.H. (1977). Contractile state of the left ventricle in man as evaluated from end-systolic pressure-volume relations. Circulation, 56, 845-852.

Higuma, N., Tsutsui, M., Toeda, T., Tamazoe, M., Matsuda, H., Kasahara, T., Arai, Y., Izumi, T., Shu, T., Tamura, K., Murooka, H. and Shibata, A. (1980). Significance of peak left ventricular systolic pressure/end-systolic volume ratio for the assessment of left ventricular contractility: Comparison of lef tventriculography and echocardiography. J. Cardiography, 10, 441-450 (in Japanese).

Itaya, M., Takahashi, H., Furuta, Y., Ogata, Y., Fujiyama, M., Jinnouchi, J., Koga, Y., Utsu, F. and Toshima, H. (1981). Clinical study of ventricular end-systolic dimension and systolic blood pressure/end-systolic dimension ratio as the indices of left ventricular function. J. Cardiography, 11, 529-541 (in Japanese).

Kats, L. N. (1960). The performance of the heart. Circulation, 21, 483-498.
Kennedy, J. W., Trenholme, S. E. and Kasser, I.S. (1970). Left ventricular volume and mass from single-plane cineangiocardiogram. A comparison of antero-posterior and right anterior oblique methods. Amer. Heart J. 80, 343-352.

Marsh, J. D., Green, L. H., Wynne, J., Cohn, P.F. and Grossman, W. (1979). Left ventricular end-syotolic pressure-dimension and stresslength relation in normal human subjects. Am. J. Cardiol. 44, 1311-1317.

Matsuzaki, M., Ishida, K., Toma, Y., Katayama, K., Matsuda, Y., Ogawa, H., Sasaki, T., Kumasa, T. and Kusukawa, R. (1980). Noninvasive evaluation of left ventricular contractility: Peak left ventricular systolic pressure-end-systolic volume relations and peak systemic pressure/end-systolic volume ratio. J. Cardiography. 10, 663-675 (in Japanese).

Mitchell, J.H. and Wildenthal, K. (1972). Problems in measurement of myocardial contractility. Proc. Roy. Soc. Med. 65, 542-545.

Nivatpumin, T., Katz, S. and Scheuer, J. (1979). Peak left ventricular systolic pressure/endsystolic volume ratio: A sensitive detector of left ventricular disease. Am. J. Cardiol. 43, 969-974.

Patterson, S. W. and Starling, E. H. (1914). On the mechanical factors which determine output of ventricle. J. Physiol. 48, 357-379.

Ross, J. Jr. (1976). Afterload mismatch and preload reserve: A conceptial framework for the analysis of ventricular function. Prog. Cardiovasc. Dis. 18, 255-264.

Sagawa, K., Suga, H., Shoukas, A.A. and BakALAR, K. M. (1977). End-systolic pressure/ volume ratio: a new index of ventricular contractility. Am. J. Cardiol. 40, 748-753.

Sarnoff, J.S. and Berglund, E. (1954). Ventricular function; Starling's law of the heart studied by means of simultaneous right and left ventricular function curves in the dog. Circulation, 9, 706-718.

Sasayama, S., Ross, J. Jr., Franklin, D., Bloor, C. M., Bishop, S. and Dilley, R. B. (1976). Adaptations of the left ventricle to chronic pressure overload. Circ. Res. 38, 172-178.

Sasayama, S., Franklin, D. and Ross, J. Jr. (1977). Hyperfunction with normal inotropic state of the hypertrophied left ventricle. Am. J. Physiol. 232, H 418-435.

Sasayama, S. and Kotoura, H. (1979). Echocardiographic approach for the clinical as- 
sessment of left ventricular function: The analysis of end-systolic pressure (wall stress) -diameter relation and force-velocity relation of ejecting ventricle. Jpn. Circ. J. 43, 357-366.

Suga, H., Sagawa, K. and Shoukas, A. A. (1973). Load independence of the instantaneous pressure-volume ratio of the canine left ventricle and effects of epinephrine and heart rate on the ratio. Ciruclation Res. 32, 314-322.

Suga, H. and SAgAwA, K. (1974). Instantaneous Pressure-volume relationships and their ratio in the excised, supported canine left ventricle. Circulation Res. 35, 117-126.

Suga, H., Sagawa, K. and Kostiuk, D. P. (1976). Controls of ventricular contractility assessed by pressure-volume ratio, Emax. Cardiovasc.
Res. 10, 582-592.

Suga, H. and Yamakoshi, K. (1977). Effects of stroke volume and velocity of ejection on end-systolic pressure of canine left ventricle, End-systolic volume clamping. Circulation Res. 40, 445-450.

Takahashi, M., Sasayama, S., Kamai, C. and Kotoura, H. (1980). Contractile performance of the hypertrophied ventricle in patients with systemic hypertension. Circulation, 62, 116-126.

Weisfeldt, M. L., Shoukas, A. A., Weiss, J. L., Dashkoff, N., Come, P., Griffith, L. S. C., Ashuff, S. C., Ducci, H. and Sagawa, K. (1976). Emax as a new contractility index in man (abst). Circulation, 54, Suppl II, II-31. 